\title{
Arbor
}

\section{Elecciones en Madrid en el cambio de siglo}

Amparo García López

Arbor CLXIX, 666 (Junio 2001), 383-410 pp.

\section{Los electores madrileños}

A partir de la ley electoral de 1890, el distrito electoral único de Madrid se dividía en 227 secciones encuadradas en los diez distritos administrativos tradicionales y cada uno de ellos compuesto de diez barrios ${ }^{1}$. De acuerdo a su población electoral ${ }^{2}$, a Madrid le correspondían ocho diputados, pudiendo elegir el votante un máximo de seis nombres.

Los distritos del Sur eran los de Latina, Inclusa y Hospital, estando delimitados los dos primeros por las calles de Lavapiés, Ronda de Valencia y Paseo de las Delicias por el Este, mientras que el Paseo de los Melancólicos, con las Cambroneras, era su límite Oeste; en su vértice Norte, Plaza de la Cebada o el Rastro, confluían una serie de ejes radiales que constituían las principales arterías viales de los distritos: Comadre, Amparo, Mesón de Paredes, Embajadores, Ribera de Curtidores, delimitación perpendicular entre Inclusa y Latina, y Toledo, límite con el distrito de Audiencia.

En este gran espacio convivían capas de mediana burguesía, ubicadas cerca de Progreso y en la calle de Atocha donde tenía su emplazamiento un sector de profesionales de farmacia y medicina en relación con el Hospital General que da nombre al distrito ${ }^{3}$, sectores populares que subsistían en condiciones deplorables en torno a la Plaza de Lavapiés, al lado de pequeños negocios familiares artesanales, alrededor de Antón Martín; con ellos, obreros de las nuevas industrias madrileñas y marginados de toda condición que, a duras penas, sobrevivían. 
De las cuatro secciones que componían el distrito de Audiencia, en torno a la calle y Plaza Mayor, es sin duda Constitución la más rica de todas ellas y muchos de sus habitantes son propietarios y ricos comerciantes domiciliados en los alrededores de la Plaza Mayor. En el extremo contrario, se sitúa el Humilladero, en las proximidades de la Plaza de la Cebada; está domiciliada en el distrito alguna figura ilustre como el duque de Osuna y del Infantado, aunque la mayoría de su población es pequeña burguesía, dedicada al comercio y la artesanía; otro tanto cabría decir del Barrio de Cava donde figura como vecino D. Manuel Becerra Bermúdez, senador y ex ministro, y del de Estudios, entre las plazas de Cascorro y Progreso, en la que tenía su vivienda el Ministro Manuel García Barzallana. La presencia de un elevado contingente de capas populares y un sector importante de empleados de escalas bajas de la Administración, presenta un distrito desigual en donde residen con los sectores señalados, una representación de ricos propietarios.

Con Audiencia, el distrito de Centro, en torno a la Puerta del Sol y la calle Arenal y el de Hospicio, articulado por el ángulo de las calles Fuencarral y Hortaleza, constituyen el núcleo del casco urbano, asiento de clases pudientes, ricos comerciantes y profesiones liberales en el que se siguen manteniendo clases altas y bajas hasta bien avanzado el S. XIX; la reordenación del suelo urbano le convertirá en núcleo comercial, elevará su valor y obligará a buscar alojamiento en el extrarradio a un contingente importante de habitantes, reduciéndose con ello la densidad de población, especialmente en Centro. Hospicio es un distrito rico aunque no uniforme, con un número elevado de propietarios, tiendas de consumo caro, un sector de empleados, menos significativo que el de Palacio, y bolsones de población de extracción popular como las ubicadas en la sección de Escorial, mientras que las de Fuencarral y Santa Bárbara albergan la mayor representación de contribuyentes y capacidades ${ }^{4}$.

En el Norte de la ciudad, los distritos de Congreso y Buenavista se articulan en torno a dos ejes aristocráticos, el formado por la Castellana y la calle de Serrano con la red de vías adyacentes perpendiculares y paralelas y el ángulo ordenado por el Paseo del Prado y el Retiro. Viven en esta zona los contribuyentes más adinerados, al lado de las figuras de mayor prestigio económico, industrial y político, presencia de empleados de la Casa Real en la sección de Retiro y militares acuartelados y trabajadores de la Administración en la calle de Alcalá.

Los distritos de Universidad y Palacio, se extendían a uno y otro lado de las calles de Ferraz y Princesa, en los alrededores del Palacio 
Real, con heterogénea población integrada por gente adinerada y capacidades ilustres que viven en las citadas calles, al lado de numerosos empleados, personal doméstico de la Casa Real y un grupo de militares acuartelados. Por el Sur de Universidad se extiende una zona de clases medias, mientras el Norte crecía notoriamente ante el asentamiento de numerosa mano de obra que retrocede ante el suelo revalorizado del corazón de la ciudad.

La distribución de la población en los distritos electorales madrileños a finales del siglo XIX, nos presenta unas zonas populares en Universidad, Hospital, Inclusa y Latina, mientras las clases acomodadas viven en Buenavista, Congreso, Palacio y Hospicio en torno a los ejes de Alcalá, Serrano, Castellana, Recoletos-Paseo del Prado, PrincesaPalacio de Oriente, Fuencarral-Hortaleza-Almagro; en el distrito de Centro, están ubicadas en Arenal-Sol y Carrera de San Jerónimo y en el de Audiencia en la calle Mayor-Sol, aunque en ambos se mantiene la presencia de ricos y pobres, debilitada al acercarnos a la liquidación de la centuria.

El fin de siglo presenta a Madrid entre la continuidad y el cambio: anclado aún en el modelo antiguo demográfico pero con síntomas de despegue poblacional, pervive todavía el trabajo artesanal y se inicia la industrialización ${ }^{5}$, mantienen su presencia ${ }^{6}$ los partidos turnantes de la Restauración aunque comienzan a ofrecer señales de agotamiento, mientras las nuevas fuerzas políticas intentan incorporarse al nuevo marco electoral del sufragio universal.

\section{El sufragio universal en Madrid}

Las elecciones a diputados en Madrid, en donde las listas de candidatos recogían las figuras mas señeras de las formaciones políticas, nos hablan del desajuste que el sufragio general produjo en el control del electorado durante los comicios de 1891 y sobre todo en los de 1893. A lo largo de la última década del siglo, la situación irá deteriorándose, como se deduce de los procesos electorales celebrados.

En la primera de las fechas mencionadas (1 de febrero de 1891, bajo gobierno conservador de Cánovas), la variedad y el número elevado de candidaturas (un total de diez entre las dos turnantes, conservadora y liberal, dos republicanas, una de coalición y otra zorrillista, la heterodoxa romerista, una socialista y cuatro independientes), supera todas las expectativas y plantea la incógnita de los apoyos financieros a personajes como Isaac Peral (retirado en última instancia por presiones 
del Partido Liberal) o Felipe Ducazcal, empresario de teatro y compañero de fatigas de Romero Robledo, que se presenta al margen de la candidatura de su benefactor. Por primera vez, la candidatura oficial conservadora no irá encabezada por Cánovas del Castillo y el honor le corresponde a un silvelista, arquitecto de profesión, el marqués de Cubas; otro arquitecto, tres títulos nobiliarios y un conocido industrial madrileño, Carlos Prast, que ya había representado al partido en 1886, completan la candidatura conservadora. El Partido Liberal de Sagasta compone su lista con dos hombres templados del liberalismo tradicional, dos figuras indiscutibles del progresismo liberal, José Canalejas y Segismundo Moret y dos representantes de la vida madrileña como el industrial Joaquín Angolotti, activo promotor de la Cámara de Comercio de Madrid.

Romero Robledo, personaje del lobby cubano por su enlace matrimonial con la hija de Zulueta, encabeza candidatura propia, la Liberal Reformista, con su incondicional Alberto Bosch y Fustegueras y otros cuatro personajes relacionados con el mundo de las finanzas o pertenecientes a la Junta Provincial, encargada de elaborar el nuevo censo del sufragio universal masculino.

Los distintos grupos republicanos ${ }^{6}$ consiguen ofrecer dos listas: una con los progresistas seguidores de Ruiz Zorrilla que irá encabezada por el médico José $\mathrm{M}^{\mathrm{a}}$ Esquerdo e integrada, entre otras figuras, por el comandante Emilio Prieto, director de la Correspondencia Militar, que invita al ejército y a los funcionarios a respaldar la oferta electoral a través de sus páginas. Los federales, centralistas y posibilistas conforman coalición, la Unión Republicana, con dos nombres de cada grupo, entre los que figuran Pi y Margall y Salmerón como elementos principales al lado de la representación posibilista del médico Angel Pulido y Federico Ortiz y López, miembro del Círculo de la Unión Mercantil ${ }^{7}$.

El partido conservador será refrendado en Palacio, Buenavista y Hospicio y sus bajos porcentajes proceden de Inclusa, Hospital y Audiencia. José Canalejas obtiene casi un empate con el primero de la lista conservadora y sus votos provienen de Centro, Audiencia y Hospital, distritos de heterogénea composición social y sectores de mediana y pequeña burguesía progresista. Los mejores resultados republicanos proceden de Inclusa, Universidad y Latina y son significativos en Centro para Nicolás Salmerón, además de Hospital y Audiencia para el médico José $\mathrm{M}^{\mathrm{a}}$ Esquerdo.

En todo Madrid los votos conservadores, a pesar de ser los ministeriales, solo aventajan a los liberales en escaso porcentaje y arrojan 
una buena calificación republicana en ambas candidaturas, con lo que, de haber ido coaligadas, el resultado espectacular de 1893 se hubiera adelantado. La quiebra del partido conservador, dividido entre canovistas y romeristas, a partir de la segunda mitad de la década de los ochenta, fue una circunstancia que aprovechan los republicanos para introducirse en las minorías electorales, a pesar de que el censo elaborado para el primer sufragio universal deja mucho que desear. Los resultados indican, por otra parte, la dificultad para controlar un electorado urbano movilizado por partidos republicanos, ante las expectativas del nuevo sufragio universal. Si es que existieron coacciones, y así parecen indicarlo algunas denuncias, la inclinación del voto en Madrid es clara; en muchas ocasiones, «a pesar de ellas» y aunque ningún candidato republicano obtuvo aquí escaño, los resultados generales a nivel del Estado llevaron al Congreso a una treintena de diputados que decidieron construir una Nueva Unión Republicana. El sufragio universal cataliza el voto emergente de los sectores populares de la zona sur de Madrid y se perfila como el feudo geográfico de la futura conjunción republicano-socialista, pero la inclinación republicana del voto en Centro y Audiencia, dibuja todavía la presencia de amplias clases medias identificadas con el proyecto liberal del sexenio.

Romero Robledo no consigue imponer a ninguno de sus hombres a pesar de las fijas clientelas del antiguo ministro de Gobernación, e irrelevantes son los resultados del Partido Socialista con una lista que encabeza el tipógrafo Pablo Iglesias acompañada de cinco trabajadores de la construcción ${ }^{8}$. Los postulados obreristas del partido, la ascendencia de la Internacional bakuninista de Fanelli en el republicanismo federal y la especial idiosincrasia de las clases populares madrileñas, con predominio de organización gremial, mas las dificultades añadidas por la carencia de medios para realizar la campaña electoral, retardarán la implantación del partido hasta el inicio del siglo $\mathrm{XX}^{9}$. Serán proclamados diputados los seis representantes del Partido Conservador y Canalejas y Moret por el Partido Liberal.

La participación general ha subido notoriamente respecto a las últimas elecciones de 1886 celebradas todavía por sufragio censitario y en ningún distrito es inferior al 50 por ciento; Universidad con Hospicio ofrecen los índices mas bajos frente a Congreso que es el mas elevado de Madrid, seguido de Audiencia, con lo que concluimos que el sufragio universal influyó en la movilización del electorado ante la concurrencia de nueve candidaturas, en esta primera consulta de la década final de siglo. 


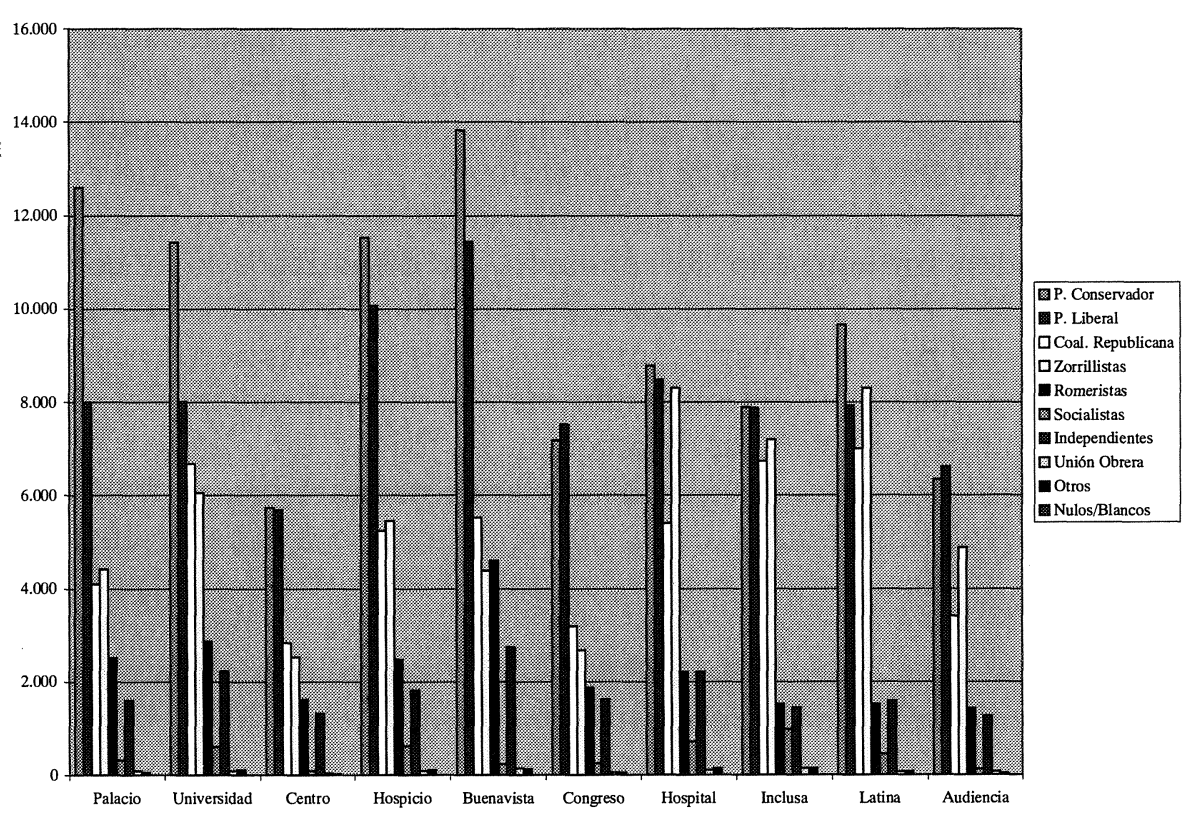

\section{Triunfo republicano en Madrid}

Las elecciones celebradas el 5 de marzo de 1893 consiguen un vuelco electoral en Madrid. El fraccionamiento ostensible del Partido Conservador con la vuelta de Romero Robledo y los puntos de vista políticos de Silvela, radicalmente distintos, traerán la dimisión de Cánovas como Jefe de Gobierno, después de someterse a una votación de confianza en el Parlamento y sufrir los resultados del amplio abstencionismo silvelista. Sagasta configura nuevo gabinete el 11 de diciembre de 1892 y disuelve las Cortes conservadoras el 5 de enero de 1893, fijándose la celebración de elecciones para el 5 de marzo.

En esta ocasión, se presentan en Madrid cuatro candidaturas: la Liberal-Dinástica con hombres nuevos del partido, conocidos en Madrid por su participación en la corporación municipal como Cándido Lara y Ortal que volverá a estar presente en las listas liberales de 1898, propietario y uno de los doscientos mayores contribuyentes de Madrid ${ }^{10}$, modelo de nueva burguesía especuladora, en este caso utilizando los contratos de limpieza y riego del Ayuntamiento; su fortuna se forjó con el suministro de acémilas del ejército del Norte en la segunda guerra carlista ${ }^{11}$; con él, representantes del Círculo de la Unión como Ramón 


\section{Elecciones en Madrid en el cambio de siglo}

Saínz o Federico Ortiz y López, hombre de Castelar a raíz de la integración de los posibilistas en el fusionismo. Los republicanos ofrecen lista conjunta bajo la denominación de Unión Republicana y en ella van los progresistas Manuel Ruiz Zorrilla y José $\mathrm{M}^{\mathrm{a}}$ Esquerdo, dos federales y dos centralistas.

Por último, se presenta el Partido Socialista con seis nombres entre los que cabe destacar la incorporación del médico Jaime Vera y una Candidatura Católica del mismo número de aspirantes bajo el patrocinio del arzobispo de la diócesis, para agrupar «en un solo haz» las fuerzas católicas separadas de todo partido político ${ }^{12}$. El Partido Conservador se abstiene de participar en la contienda y su presencia en la campaña electoral se limitará a la recomendación de Cánovas a los votantes conservadores para que apoyen la candidatura liberal en Madrid, «porque el triunfo de los republicanos en la capital será el triunfo de la República» ${ }^{13}$.

La coalición republicana consiguió imponer los nombres de sus seis candidatos, siendo el más votado José $\mathrm{M}^{\mathrm{a}}$ Esquerdo que recibe su apoyo de Inclusa, Latina, Hospital y Universidad, aunque también es significativo el número de votos de Audiencia y Hospicio, mientras ha desaparecido el Centro como bastión republicano. La candidatura liberal obtiene dos actas de diputados y los mejores porcentajes provienen de Palacio, Buenavista y Congreso, seguidos de los de Centro. El júbilo de los resultados electorales se traduce en el triunfalismo de los comentarios editoriales de los periódicos republicanos, dando la bienvenida al advenimiento de la República en Madrid que se hará extensiva a todo el Estado, en clara alusión a la idea de que la «toma de la capital» era prioritaria en la estrategia electoral de todos los partidos políticos ${ }^{14}$.

La candidatura católica integrista, con menor pero significativo porcentaje en todo Madrid, será refrendada en los distritos ministeriales de Buenavista y Congreso, superados por el de Centro donde serán mas votados. La asociación del catolicismo con el partido conservador preconizado por Silvela, tuvo que conformarse en este caso con la movilización del electorado en pro de una candidatura confesional y, a pesar de sus modestos resultados, son el inicio de una militancia expresa antirrepublicana, bajo la bandera de la regeneración política. El número de votos del Partido Socialista es inferior al de la anterior elección y provienen de Inclusa, Hospital y Universidad ${ }^{15}$, siendo Centro, Audiencia y Congreso los distritos de menor votación socialista. Éstos resultados acrecientan las críticas republicanas, al día siguiente de las elecciones: «... Nunca nos ha movido animosidad contra los obreros del llamado Partido Socialista, ni aún cuando con mas saña y mas groseros epítetos han combatido a los partidos republicanos. Hoy, después del fracaso de la candidatura socialista en Madrid, después del ridículo éxito que han logrado quedando 
por debajo de la candidatura católica, no habíamos de amargar mas aún su derrota con frases de censura... La mayor parte de los obreros han votado la candidatura republicana, y prueba de ello, es que han tomado parte en la votación el $60 \%$ de los electores inscritos en el Censo» ${ }^{16}$. La rivalidad por el voto obrero es evidente entre ambas formaciones hasta que aparezcan las futuras candidaturas republicanosocialistas.

La denuncia de coacciones electorales se producirá también, en esta ocasión, en dos de los sectores sociales mencionados en todas las consultas. La minoría republicana representada en el Ayuntamiento y en la Diputación Provincial desde 1892, hace pública la presión que ciertos empleados ejercen entre sus compañeros para inclinar el ánimo a votar la candidatura ministerial. Los otros dos colectivos, sensibles a las influencias institucionales, serán los funcionarios de las instituciones de Beneficencia y las clases pasivas, a las que su Junta Directiva envía una circular recomendando la candidatura ministerial, con la promesa de Sagasta de equiparar los descuentos de sus haberes a los de los empleados activos. Otra forma de engaño a los electores es la falsificación de papeletas republicanas en las que se suprime el nombre de uno de los candidatos y se sustituye por el de alguno liberal, mientras un periódico conservador comenta el triunfo republicano con la editorial titulada «El Cunero», aplicando su denominación a los republicanos ${ }^{17}$.

GRÁFICO 2. Elecciones 1893

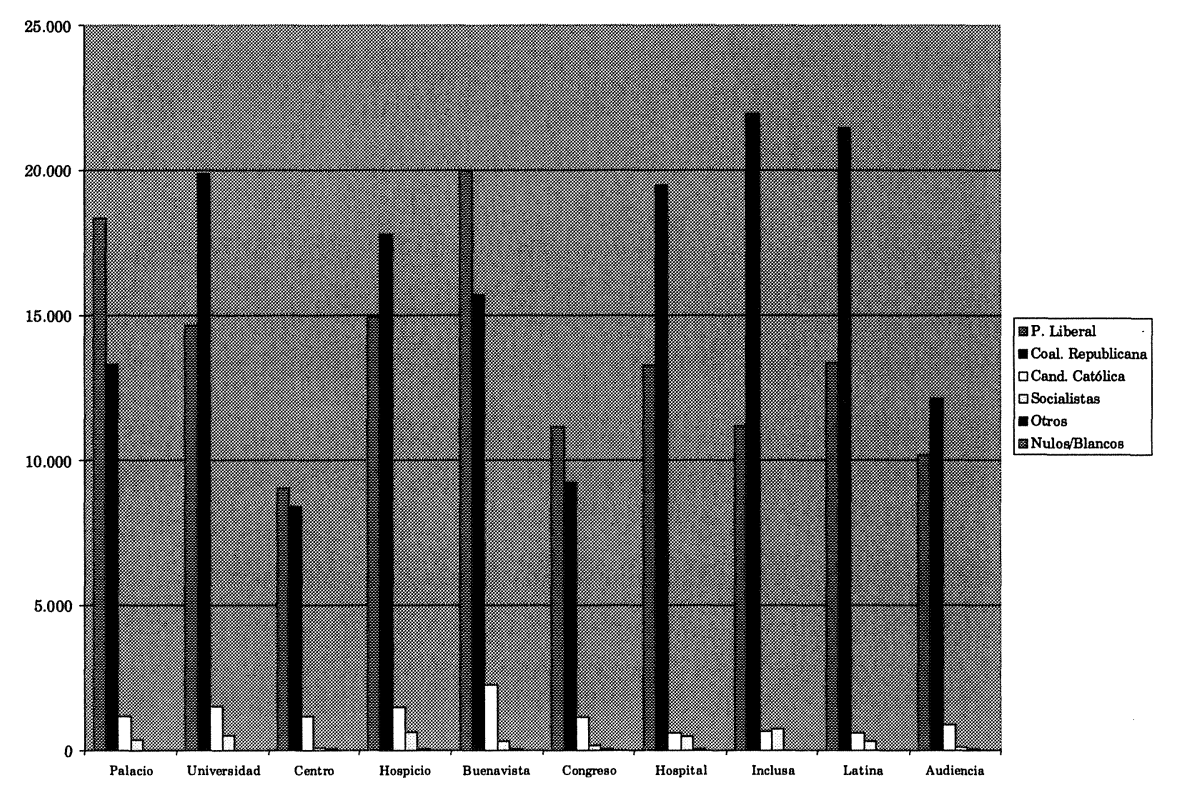




\section{La recuperación del turno}

Desde finales de 1894 el gobierno liberal de Sagasta estaba encontrando serias dificultades por el incremento del gasto público que acarreaban los territorios ultramarinos y que inevitablemente repercutían en la opinión pública. El partido había integrado a un sector de republicanos posibilistas $\mathrm{y}$, ante el ataque realizado por jóvenes cuadros del Ejército a las oficinas de redacción de los periódicos «El Resumen» y «El Globo», ofendidos por los comentarios vertidos en ellos, Sagasta defiende la libertad de expresión frente a actitudes benevolentes de altas jerarquías del ejército. La Regente le retira su confianza y Cánovas forma gobierno conservador el 23 de marzo de 1895, acordando con Sagasta y la Reina la continuación de las Cortes liberales de 1893 hasta la aprobación del presupuesto económico. Esta curiosa situación se prolongará durante casi un año. Sin embargo, graves incidentes van a producirse de nuevo por la administración municipal a propósito de que Romero Robledo fuese nombrado ministro del Gobierno con dos de sus leales, uno de ellos el ex alcalde Bosch y Fustegueras, causante de la caída conservadora de 1892.

El marqués de Cabriñana denunciará públicamente a los administradores municipales romeristas por haber intentado sobornarle a propósito de unos terrenos de su propiedad incluidos en un proyecto de ordenación urbana. La imponente manifestación de protesta organizada en Madrid por silvelistas, liberales y republicanos, provoca el cese en el gobierno de los romeristas y Cánovas se apresura a disolver las Cortes ante un posible voto de censura. El Decreto está firmado el 28 de febrero de 1896 y se convocan elecciones para el 12 de abril en medio de un ambiente de expectación ante las graves noticias que venían de Cuba.

A la altura del mes de abril de 1896, con el trasfondo de la guerra cubana, el panorama electoral nos habla de crisis profunda de la Monarquía Constitucional. En esta ocasión, la canđidatura conservadora en el gobierno, refuerza el carácter nobiliario en el que se funden la vieja y la nueva cuna: tres títulos como el duque de Bailén integrado en la Liga de Propietarios ${ }^{18}$ que recogía a unas 250 familias, incluido a última hora en las listas, al lado del banquero Benito Rolland dedicado a la adquisición de terrenos para su conversión posterior en rentas inmobiliarias ${ }^{19}$ y el industrial Teodoro Bonaplata también beneficiario de la gran especulación del suelo que poseía en la Plaza de Sta. Bárbara, donde, por cierto, tenía también su vivienda, el anterior candidato ${ }^{20}$. Los liberales dinásticos de Sagasta presentan únicamente tres nombres que figuraban ya en 1893; uno de ellos Federico Ortiz y López, tendrá como contrincante a un personaje «independiente», Julio Urbina, marqués de Cabriñana, que se presenta 
apoyado por un sector del mismo Círculo y por Silvela que aspira a conseguir la consolidación de su Unión Conservadora frente a la ortodoxia Canovista. Es aupado por una prensa sensacionalista que destapa las corrupciones del Ayuntamiento de Bosch y Fustequeras, socio indispensable de Romero y Robledo ${ }^{21}$. Mientras tanto, Silvela reafirma su postura antigubernamental sosteniendo que el conflicto cubano «tiene, a su entender, un aspecto más político que militar».

La campaña electoral gris y aburrida destaca por las continuas alusiones a la guerra colonial y sus implicaciones en la estabilidad política, en el turno de partidos, y en última instancia, en la de la Monarquía que sustentaban. Destacamos el siguiente comentario: «la cuestión de Cuba es para España la primera de nuestras cuestiones nacionales... El poder público se encarna en una bien establecida Monarquía y en gobiernos fuertes y duraderos... $\mathrm{Ni}$ el soberano, ni sus ministros tienen que preocuparse de vivir un día, una hora, un minuto más» y en días posteriores, pone al descubierto su temor por el posible descrédito de la Corona ante la sangría de la guerra cubana. "No se diga que el retraimiento es una protesta contra la obra de la monarquía» 22 .

Para asegurar los ocho escaños que a Madrid le corresponden, el Partido Conservador presenta cinco nombres y tres el liberal, siendo proclamados finalmente los ocho como diputados. Ahora bien, si los partidos turnantes pudieron ganar con impunidad se debió, en parte, a la inhibición de las organizaciones republicanas, enfrascadas en luchas internas a la hora de definir desgastadas tácticas y estrategias de lucha, mientras muchos de sus jefes prestaban decidido apoyo a la guerra contra el «separatismo cubano» ${ }^{23}$. Sin embargo, la ausencia de enfrentamientos entre los grupos institucionalizados durante toda la campaña electoral es claro síntoma de la necesidad que tienen ambos para frenar el ascenso de los que iniciaban su andadura política y habían demostrado en anteriores consultas gran capacidad para movilizar a las masas.

El partido del gobierno obtuvo un amplio refrendo con casi el sesenta y ocho por ciento de votos y un porcentaje de participación del sesenta y dos por ciento, el más alto de los registrados hasta la fecha. Acompañado del retraimiento republicano, resulta altamente sospechoso, máxime cuando los mayores índices son compartidos por Latina, bastión popular pero con clientelismo romerista y Palacio reducto gubernamental por excelencia.

Los ridículos resultados republicanos y el descenso de votos al Partido Socialista, a pesar de la popularidad y prestigio de sus tres candidatos, indican que las clases populares han seguido la llamada a la abstención republicana ${ }^{24}$, ya que la agrupación socialista madrileña había lanzado un manifiesto condenando el retraimiento electoral a la vez que pedía el 


\section{Elecciones en Madrid en el cambio de siglo}

inmediato final de la guerra de Cuba, entre otras razones porque la quinta de 25.000 hombres que Cánovas había decretado, pese a que el Capitán General de Cuba afirmaba no necesitar más soldados, con el propósito de provocar una afluencia de reducciones en metálico ${ }^{25}$ centraba toda la atención de una población que se quedaba sin mano de obra en sus hogares. La guerra, mas que las elecciones, tenía también especialmente ocupados a fuertes sectores coloniales y financieros, tradicionales apoyos del Partido Conservador. La descomposición del partido no sólo era el resultado de la disidencia silvelista.

El caciquismo gubernamental es más notable en estas elecciones, incluso en Madrid, en donde el Alcalde presidente impone la obligatoriedad del voto a los funcionarios del Ayuntamiento; el control de la capital se realiza además empleando los mecanismos que brinda la ley electoral de 1890, como son los de colocar efieles interventores en las diminutas secciones en que se ha dividido el distrito único de Madrid» ${ }^{26}$.

El doctor Esquerdo, republicano zorrillista que fue el hombre más votado en 1893, comentando las cifras electorales, denuncia que el gobierno estaba obligado a fingir ese resultado escandaloso por razones de interés monárquico para demostrar que el retraimiento acordado por los republicanos no influía en la vida nacional «... Pero con ello, concluía, se ha realizado un flaco servicio a la Monarquía avergonzada de tanto atropello... necesitándose la revolución como única salvación de la patria» ${ }^{27}$.

GRÁFICO 3. Elecciones 1896

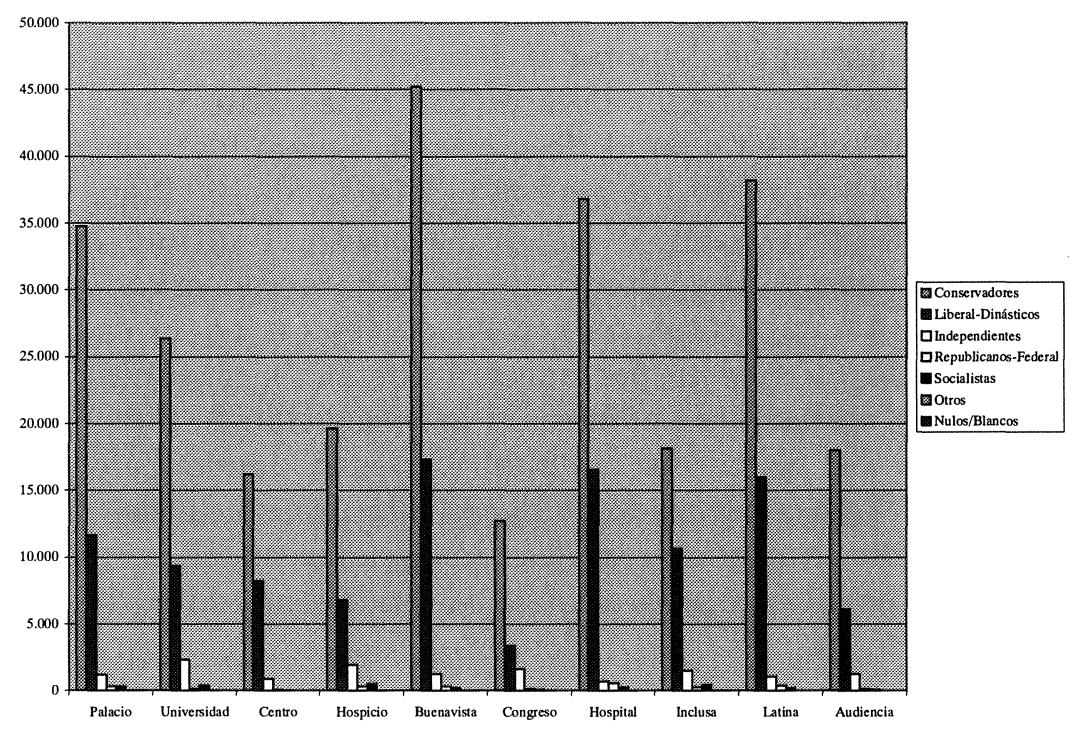




\section{Elecciones en tiempo de guerra}

Las medidas extremas que el gobierno conservador de Cánovas impuso a propósito de la política colonial y en aras de la permanencia de la soberanía española en los territorios coloniales (presupuestos especiales, envío de soldados, procesos dudosos de anarquistas, realizados por tribunales militares que incluyeron cinco penas de muerte), desembocaron en un clamor de las clases populares por las medidas que atentaban contra los trabajadores. La primera respuesta sería el asesinato de Cánovas en 1897, por la mano de un anarquista italiano y, con su desaparición, se acelera la crisis del sistema. Después de la interinidad conservadora del general Azcárraga, la Regente llama a Sagasta a formar gobierno, tarea que realiza entre el 2 y el 4 de octubre. Las Cortes conservadoras de 1896, suspendidas desde el 2 de junio de 1897, son disueltas el 26 de febrero de 1898 y se convocan elecciones para el 27 de marzo.

La campaña electoral pasa a lugar completamente secundario ante el ambiente de guerra y sentimientos ultrapatrióticos que hacia respirar la clase política del Régimen y proporciona a los socialistas un excelente instrumento de propaganda en un momento en que el partido tenía en su organización un total de diez mil federados después del V Congreso de la UGT celebrado en Valencia en 1896. Como Pi y Margall, se oponía a la guerra y censuraba a los anarquistas su activismo y «propaganda de hecho».

En la circunscripción de Madrid se presentan para ocupar los ocho escaños del Congreso de Diputados los siguientes aspirantes: Los liberales dinásticos repiten nombres de las listas anteriores de 1896 y 1893, y añaden, hasta un total de cinco, dos significativos personajes de la vida madrileña, relacionados con el Círculo de la Unión Mercantil como Ramón Saínz y Pablo Ruiz de Velasco. El último apellido de una saga de comerciantes (Bonifacio: candidato conservador en 1879 era dueño de una importantísima casa de tejidos en la calle Postas) participará en su fundación, pertenecerá además a la Junta Provincial de Agricultura, Industria y Comercio, a la Asociación de Fincas Urbanas y a la Cámara de Comercio de Madrid desde donde defendía el librecambismo ${ }^{28}$. Los conservadores de Silvela presentan dos personajes del moderantismo, antiguos carlistas integrados en el partido conservador, pero es de nuevo la candidatura «independiente» del Marqués de Cabriñana, la que fustiga a Romero y Robledo y su grupo cubano con el aval de otro sector del Círculo de la Unión y el de Silvela. Los republicanos tienen dos candidatos, ausentes hasta ahora en las 
listas electorales; uno de ellos, el centralista Constantino Rodríguez, era hermano de Gabriel, candidato en 1879, impulsores ambos de la Institución Libre de Enseñanza y dueños de unos conocidos almacenes de curtidos y artículos de tapicería, pagando trescientas pesetas de contribución. En calidad de comerciante local pertenece al Círculo de la Unión Mercantil y también a la Liga de Contribuyentes y Propietarios, siendo concejal en las elecciones municipales de 1887 por el distrito de Centro. Rodríguez Hermanos aparece en la lista de Bancos, banqueros y comerciantes más importantes en $1895^{29}$; fue Senador por Puerto Rico y colaboró en la Sociedad Abolicionista. Por el Partido Socialista van los dos candidatos conocidos de anteriores elecciones, Pablo Iglesias y Jaime Vera.

La persistente idea que subyace en los comentarios de prensa de la campaña electoral expresa la necesidad de mantener un normal funcionamiento de las instituciones para salvar la prioritaria, la Monarquía, dañada por el interminable conflicto de Ultramar. Bajo esta perspectiva, Carlos Serrano publicó en 1984 un libro en el que expone la sugerente hipótesis en boca de Woodford, a la sazón embajador norteamericano en España, según la cual los ministros de la Regencia preferían «las probabilidades de una guerra, con la seguridad de perder Cuba, al destronamiento de la dinastía» ${ }^{30}$. La suya no es una opinión aislada, ni carente de verosimilitud si recordamos otras visiones historiográficas del Desastre ${ }^{31}$.

Los resultados de las elecciones, de confirmación confụsa a través de los datos suministrados por el Ministerio de Gobernación y la prensa coetánea, son los siguientes: el más votado será el cabeza de lista liberal, que obtiene acta de diputado, seguido por los otros aspirantes de partido con apenas cuatrocientos votos de diferencia entre cada uno de ellos. La cifra desciende algo más con el Marqués de Cabriñana, que también es proclamado vencedor con uno de los conservadores y un republicano. Como en las elecciones de 1896, vuelve a repetirse la jugada gubernamental, en este caso liberal, con la proclamación de sus cinco candidatos presentados y añade una variante en las tres actas restantes: el partido conservador obtiene una de los dos nombres presentados, mientras se hace con el sexto puesto el candidato independiente, marqués de Cabriñana, que se había quedado en puertas en la elección anterior, consiguiendo además escaño uno de los dos republicanos. La clave del "anómalo» resultado hay que buscarla en los enfrentamientos internos de organismos influyentes de la vida económica madrileña, como son el Círculo de la Unión Mercantil y la Cámara de Comercio. La lista liberal contiene dos significativos miem- 
bros de ambas, en especial la del prestigioso Pablo Ruiz de Velasco que representa a un importante sector de todas las actividades económicas de la ciudad, burguesía madrileña dispuesta a competir con las emergentes de la periferia, pronto organizadas en partidos nacionalistas, por el nuevo reparto económico español y mundial que se vislumbraba en el fin de siglo, uno de cuyos síntomas era la guerra que se libraría con los EE.UU. en suelo cubano; igualmente este es el caso del diputado republicano. Frente a su modelo de dirección y orientación económica, otro sector del Círculo opta por apoyar al Marqués de Cabriñana, a quién respaldaba también Silvela, ahora al frente del Partido Conservador, desaparecido Cánovas del Castillo, y en competencia con el activo lobby cubano al que Romero Robledo pertenecía ${ }^{32}$.

El Partido Socialista proclama por primera vez que han sido despojados de sus actas representantes de su formación política. A propósito de los atropellos gubernamentales, comenta el periódico liberal-progresista El Imparcial: «No fue grande la animación electoral en Madrid, tampoco parece que haya sido extraordinaria en provincias... Las elecciones no habrían presentado rasgo especial... sin la conducta inexplicable de los agentes del gobierno con los electores de oposición en Vizcaya. Nadie acierta los motivos que hayan podido inducir al ministerio del Señor Sagasta a procederes de arbitrariedad y de violencia, graves siempre y gravísimos en las circunstancias actuales ...» ${ }^{33}$.

"Indiferencia y corrupción», titulaba la editorial de El País a propósito de la jornada electoral ${ }^{34}$, mientras destacaba las responsabilidades de los partidos políticos en cuanto que unos no habían expuesto lo que pensaban acerca de los difíciles problemas planteados y los más habían buscado, por el atajo del influjo oficial, lo que no eran capaces de conquistar por el camino de la opinión pública. «En Madrid el gobierno se desentendió de las elecciones, cuya dirección dejó encomendada al Alcalde, que ha hecho toda clase de esfuerzos para proteger no a los ministeriales, sino a los dos candidatos de la Unión Conservadora...por quiénes ha demostrado el cuerpo electoral un desdén rayano en el desprecio... La Candidatura Republicana no despertaba entusiasmo, ni siquiera cariño. Nació tarde y mal. Tenía el pecado de origen de haber nacido para entorpecer la Candidatura Nacional y además ha servido únicamente para aumentar la discordia entre los republicanos. Decididos los más por el retraimiento, la candidatura de fusión ha tenido la virtud de aumentar el número de aquellos con muchos fusionistas. Con los federales que siguen al Sr. Pi y Margall los cuáles, por poderosas razones, no podían votar a esos candidatos. Y lo que ha pasado en Madrid es reflejo de lo sucedido en toda la Nación...». 


\section{Las últimas elecciones del siglo}

Las nuevas Cortes se abren el 20 de abril con un mensaje de la Corona en un ambiente de patética expectación. Nadie ignoraba ya que la guerra estaba virtualmente declarada $y$, ante los graves acontecimientos, serán suspendidas desde el 14 de septiembre junto con las garantías constitucionales, hasta el 20 de febrero de 1899. Sagasta planteará la crisis liberal a la Regente por la disidencia de Gamazo y sus 88 parlamentarios. La Reina encargará a Silvela, nuevo jefe conservador, la formación de gobierno quién se hará cargo del poder ejecutivo el 4 de marzo de 1899, convocándose nuevas elecciones para el 16 de abril del mismo año. La crisis colonial ha dejado también su huella en el edificio de la Restauración.

El descrédito y agotamiento del Partido Liberal era evidente después de configurar un Estado liberal de Derecho entre 1881 y 1890. Durante la década de los noventa le tocaría liquidar los errores de una política ultracolonialista al ceder a las exigencias conservadoras y a los voraces intereses de distintos grupos de presión a los que, por otra parte, pertenecían algunos de los cabeza de lista de su propio partido político. Este hecho, sin duda, impidió la necesaria renovación de su aparato ideológico y la avanzada edad de Sagasta abría la lucha por la jefatura del Partido sin alternativa independiente de la oligarquía dominante, con excepción de la inquietante figura de Canalejas ${ }^{35}$.

El primer gobierno conservador de Silvela iniciaba su andadura con la convicción de que, contando con las figuras de Polavieja y Durán y Bas en las Carteras de la Guerra y Justicia respectivamente, la orientación descentralizadora permitiese, a través del proceso electoral, englobar el problema catalán a la vez que atraía a la derecha católica, desengañada del carlismo, a raíz del fallido levantamiento dirigido por el marqués de Cerralbo, delegado del pretendiente y con apoyos de sectores del ejército; con esta maniobra, el partido adquiriría una carga integrista y pretendidamente integradora, enarbolando la bandera de la moralidad política «española».

Las oleadas crecientes de regeneracionismos, regionalismos y nacionalismos que corrían también por Europa no insertan al naciente movimiento obrero, ni hacen frente a las necesidades sociales que conlleva una actividad económica de mayor vitalidad. Las tensiones entre las Cámaras Agrícolas de Gamazo y Costa, las Cámaras de Comercio que no llegarán a organizarse como partido y el autonomismo catalán, burguesía periférica que pierde mercados ultramarinos y está dispuesta a defender sus intereses sin intermediarios que considera ineptos, cuan- 
do no nocivos, son claro exponente de unas clases censitarias enfrentadas entre sí, a la vez que intentan contener a la clase obrera.

En este ambiente político, se presentan en Madrid dieciséis candidatos a diputados ${ }^{36}$. Los cinco del partido conservador son, en su mayoría, títulos nobiliarios, siguiendo la tendencia de la anterior convocatoria además del villaverdista Mariano Muñoz Rivero.

El Partido Liberal lleva tres nombres en la lista: el Conde de Garay, uno de los mayores contribuyentes, dueño de tres casas, Concejal del Ayuntamiento, tres veces Teniente de Alcalde y otras tres Diputado además de Senador, cargo que ostentará posteriormente con carácter vitalicio, además de obtener título nobiliario; le acompañan Joaquín Ruiz Jiménez, Senador, dueño de cuatro casas y Diputado en Madrid y el conocido Ramón Saínz. La Unión republicana ofrece al centralista Constantino Rodríguez, que ha ido ya en 1898, y dos republicanos federales, que «recomiendan ayudar a los candidatos del Partido Socialista» ${ }^{37}$. Esta formación repite de nuevo con los anteriores aspirantes, además de aparecer también un socialista independiente.

Atención especial dedican los principales periódicos ${ }^{38}$ a la actuación de las Cámaras de Comercio que acababan de celebrar una Asamblea en Zaragoza y habían hecho públicas sus demandas al nuevo gobierno «Que se les gobierne con acierto y se les administre con fraternal interés. Que la Hacienda entre en orden y los tributos se repartan con equidad. Que no haya presupuestos amañados y que los gastos públicos se reduzcan a la cantidad que la nación pueda soportar sin violencia. Que no se falte al sufragio para que la corriente sana de los electores vuelva a la vida pública». Uno de sus mas insignes representantes, Ruiz de Velasco que se había presentado en la anterior consulta, se baraja como posible candidato con Ortueta y Ramón Saínz para ser apoyado por los liberales 39; solo el último aparecerá finalmente en las listas. El gobierno considera que sus demandas son razonables pero generales y pueden ser suscritas por la clase comercial o por cualquier otra de la sociedad española. Respecto a su firme decisión de no aspirar a gobernar sino únicamente a la de «marcar a los gobiernos legal y honradamente el camino que deben seguir para evitar nuevas desdichas» ${ }^{40}$, el Sr. Silvela contesta que sus deseos están llevándose a la práctica por el actual ejecutivo por lo que no considera justificada su desconfianza extensible a todos los políticos, conviniendo en que si bien las Cámaras profesionales no deben ser un partido político, ya que «no hay partidos políticos sin políticos profesionales», sí deben tomar parte en las elecciones, movilizando al electorado y apoyando a aquellos candidatos que acepten sus programas y lleguen a sentarse en las Cortes para «hacer país». 


\section{Elecciones en Madrid en el cambio de siglo}

Los resultados ${ }^{41}$ confirman la tendencia de anteriores elecciones, siendo proclamados los cinco conservadores con un número de votos similar en todos ellos, y los tres liberales con la mitad de los primeros. Los apoyos mayoritarios para los ocho candidatos provienen de Buenavista, Palacio y en menor medida de Congreso y Audiencia. Los republicanos, que comienzan a igualarse con el Partido Socialista ( $\mathrm{Pi}$ y Margall y Pablo Iglesias obtienen cerca de cinco mil quinientos en Madrid), son mas votados en Universidad, Hospital e Inclusa. La lenta implantación de los socialistas comienza a ser motivo de atención de la prensa conservadora ${ }^{42} \mathrm{y}$, a pesar de que el independiente Eusebio Blasco merma un puñado de votos a su candidatura, denuncian que «... en Madrid, un candidato socialista debió obtener acta... pero los agentes del gobierno repartieron sus votos a los demás candidatos... Si existiese pureza electoral, el Partido Socialista tendría a lo menos seis representantes en las Cortes». Serán más votados en Inclusa y Universidad.

De cualquier forma, y a pesar de los propósitos de Silvela de realizar unas elecciones limpias, movilizando su propio electorado con las nuevas generaciones conservadoras, el abstencionismo en Madrid volvió a alcanzar cifras superiores al sesenta por ciento y aunque estas nuevas Cortes serían las de «la paz», la amenaza carlista, las díscolas clases medias organizadas en partidos políticos y los desórdenes sociales no parecen conjurarse en este primer intento del regeneracionismo conservador, a pesar de que los grandes de España ocupasen páginas de los periódicos con discursos enaltecedores de la Patria. Las secuelas de la guerra en Filipinas, los haberes de los repatriados y los prisioneros de las islas, coinciden en los titulares de prensa con la noticia sobre el final de la cuestión Dreyfus ${ }^{43}$.

\section{Primeras elecciones en el nuevo siglo}

La última etapa del gobierno conservador de Silvela, caracterizada por la aprobación de leyes presupuestarias y tributarias y las primeras medidas de carácter social, promovidas por Eduardo Dato èn Gobernación ${ }^{44}$ no parecen adecuadas a sectores de la burguesía catalana provocando la dimisión de los ministros catalanes y la conversión de los polaviejistas en catalanistas con lo que, en 1900, el regionalismo político catalán se lanzará por separado a la arena política.

Igualmente fracasará el intento de integración liberal, con la presencia en el gabinete conservador del director de «El Imparcial» Rafael 
Gasset y de García Alix como Ministros de Fomento y de Instrucción Pública respectivamente. Las maniobras militares de los generales Linares, Ministro del Ejército y Weyler, nombrado capitán general de Madrid, sin conocimiento del Consejo, originará la dimisión fulminante de Gasset y Dato y con ella, la caída de Silvela.

Durante el ministerio puente del General Azcárraga, el matrimonio de la princesa de Asturias, hermana del rey Alfonso con el hijo de un eminente carlista, concita el problema religioso ante el creciente poder de las órdenes religiosas dedicadas a la enseñanza y la respuesta anticlerical de las fuerzas políticas, incluido el Partido Liberal. En última instancia, el gobierno llevará a efecto la suspensión de garantías constitucionales y la declaración del Estado de Guerra, restablecidas por el nuevo gabinete liberal de Sagasta y Moret en el mes de marzo de 1901. El gobierno convoca elecciones para el 19 de mayo, con dificultades electorales añadidas, ante el giro inquietante adoptado por el regionalismo de la Unión Nacional de Paraíso y Costa y el alumbramiento del anarcosindicalismo en el campo andaluz y Cataluña a raíz del Congreso anarquista celebrado en Madrid en el mes de octubre de 1900.

Los aspirantes a ocupar los ocho escaños que a Madrid le corresponden son los siguientes: el Partido Liberal presenta seis nombres, conocidos algunos en anteriores elecciones y ligados la mayoría a los centros económicos del Círculo Mercantil y la Cámara de Comercio, entre los que cabe destacar a Mariano Sabas Muniesa, que figura entre los mayores contribuyentes de la ciudad, pagando alrededor de seis mil pesetas anuales, Concejal del Ayuntamiento y Primer Presidente de la Cámara de Comercio e Industria de Madrid; profesor mercantil, se dedica a las finanzas a través de la Banca Muniesa en Preciados 84. Su arraigo en la vida industrial y comercial de Madrid queda claramente expuesta al serle encargado en 1906 el apartado de «Madrid industrial y comercial» para la redacción de la Guía de Madrid ${ }^{45}$. Silvela únicamente ofrece dos candidatos, uno de ellos el villaverdista Mariano Muñoz Rivero que estaba en las anteriores elecciones de 1899. Romero Robledo que preside la Junta Provincial del Censo ${ }^{46}$, confecciona una lista de seis aspirantes bajo la denominación de Coalición Democrática Nacional que él mismo dirige. De nada ha servido el intento de agrupamiento conservador-liberal de finales de siglo: el inicio del nuevo ofrece una lista liberal pura y la ruptura de los conservadores en romeristas y silvelistas. Hasta 1903 no encontraremos configuradas electoralmente las Uniones Monárquicas con candidatura conjunta de conservadores y liberales. De igual modo, seis nombres van por la 
Coalición republicana, última a la que concurrirá Francisco Pi y Margall, antes de su muerte.

La Unión Nacional ${ }^{47}$ tiene en Madrid dos candidatos, Juan Clot y Sebastián Maltrana Novales, éste último conocido como independiente en las elecciones de 1884 en las que reclamaba su puesto en la política ${ }^{48}$, comerciante adscrito al gremio de la papelería, miembro activo del Movimiento Asociativo de Comerciantes madrileños desde los años ochenta, socio del Círculo de la Unión y Presidente del Sindicato de la Industria y del Comercio de Madrid en 1882. Ocupaba igualmente un puesto directivo en la Sociedad de Comisionistas y Viajantes y será Vicepresidente de la Asamblea de Cámaras celebrada en Barcelona en 1904, teniendo el sillón presidencial de la Cámara de Comercio e Industria entre 1905 y $1908^{49}$. De nuevo los nombres de Pablo Iglesias y Jaime Vera por el Partido Socialista.

Los titulares de prensa comentan los discursos republicanos de candidatos conectados con las Sociedades de Amigos del País que movilizan al electorado en los distritos de Latina, Inclusa, Universidad y Hospicio; la reclamación de Maltrana ante el Ayuntamiento por las exclusiones del censo de un significativo número de votantes y la posible candidatura de Paraíso, representando en Madrid a la Unión Nacional; finalmente, el destacado dirigente viene a la capital a cerrar la campaña electoral en apoyo de los dos citados aspirantes. La dificultad de configurar la definitiva lista liberal es mencionada en comentarios que aluden a la posible huelga de los ministeriales mientras la declaración del Estado de Guerra y suspensión de garantías en Barcelona con la prohibición de un periódico catalanista en Madrid y la noticia de la huelga de mineros, destacan la tensión social y política que acompaña al período electoral. ${ }^{50}$

La desmovilización y la apatía son, sin duda, los ganadores de esta jornada que obtiene cifras de participación parecidas a las de la anterior de 1899. El panorama político y económico ha repercutido en profundidad y el desasosiego de las clases medias les conduce al abstencionismo, mientras los liberales se siguen negando a la entrada en el Parlamento de los socialistas y hubiesen preferido que los regionalistas no llegasen a él.

Serán proclamados diputados los seis aspirantes liberales; los silvelistas obtienen un escaño, con cinco mil ochocientos votos para Mariano Muñoz Rivero, mientras los romeristas no consiguen sentarse en el Parlamente por la capital, pues su candidato mas votado, Juan Correcher con cuatro mil seiscientos votos, se queda por debajo de $\mathrm{Pi}$ y Margall con cinco mil cuatrocientas cincuenta y casi a la altura de 


\section{Amparo García López}

los cuatro mil cuatrocientos de Pablo Iglesias; en cambio tiene acta de diputado José Clot por la Unión Nacional, con seis mil ochocientos votos, en parte por el prestigio y respaldo que acompaña a su reciente cargo al frente del Ayuntamiento de Madrid (de 1897 a 1899) ${ }^{51}$. Sin embargo, el fracaso electoral general del partido llevará a la Unión Nacional a abandonar la batalla de las urnas y así, el otro candidato, Maltrana, integrará la candidatura monárquica de 1905 por los liberales.

Los comentarios de prensa acerca del transcurso de la jornada electoral no pueden ser mas desalentadoras, con urnas que apenas reunían una treintena de votos y a los que el presidente del colegio añadía unos pocos más, en ausencia de algún interventor republicano; los lázaros resucitan de nuevo en Latina y es Universidad la que ofrece algún altercado de mayor transcendencia, denunciado por interventores republicanos y socialistas «que en este distrito tiene un indiscutible fuerza» ${ }^{52}$. Una vez mas la intervención gubernamental preside estos comicios, influyendo notablemente en sus resultados.

El nuevo parlamento de mayoría liberal se abre con un número significativo de minorías, mas divididas que en ningún otro de la Restauración ya que una parte de los llamados independientes son regionalistas de distinta procedencia. Alfonso XIII juraría la Constitución un año después.

\section{Conclusiones:}

El estudio de periodos electorales requiere en Madrid atención primordial en dos aspectos derivados del hecho de su capitalidad. La composición sociológica de su electorado y la personal de los aspirantes a diputados, figuras relevantes de la política local pero coincidentes en ocasiones, con representantes notorios de ámbito nacional, debe de tener correspondencia en la confección de listas que combinen ambos extremos. El sector del comercio y la industria, numéricamente significativo en una ciudad especializada en el consumo de amplias capas de la población, pero variado en cuanto a la complejidad de sus negocios, se compone del grupo de ricos comerciantes, concentrado en la Puerta del Sol y aledaños, y el pequeño comercio e industria, diseminados por la geografía madrileña del recinto mas vetusto de la ciudad. Ellos son el claro exponente de que la política de Madrid no es el resumen de la nacional. En el comportamiento electoral del sector se observa una evolución significativa desde sus primeros apoyos al régimen recién instaurado con una amplia votación al partido conservador en 1876 
y en las siguientes elecciones, celebradas tres años mas tarde, la integración en la candidatura conservadora de dos de sus representantes, relevantes por su vinculación con sectores del Círculo de la Unión Mercantil, parecía asegurar una clientela importante durante los próximos años. El inicio de la década de los ochenta vendrá acompañado de los primeros síntomas de desavenencias; el Partido Conservador perfila su lista con hombres ligados a Romero Robledo y son los intereses cubanos los que se afianzan en el seno de su familia. Tampoco el Partido Liberal ofrece un panorama alentador, y en 1881 un significativo comerciante irá acompañado de dos banqueros, un síndico de la Bolsa y el Marqués de Campoo, nobleza caracterizada por la escasa cuantía de sus inversiones en actividades empresariales ${ }^{53}$. La batalla por la supresión de obstáculos para el desarrollo de la actividad mercantil llevará ese año a Gabriel Rodríguez, Presidente de la Asociación Librecambista y al industrial que estaba al frente del Círculo Mercantil, a intentar la representación en el Parlamento a través de su electorado comerciante, ofreciendo una opción alternativa a las dos turnantes, malograda por las maniobras de los partidos institucionales que vaciaron la candidatura mercantil, integrando a uno de ellos en la lista liberal $\mathrm{y}$ sin puesto en el Congreso ${ }^{54}$. La misma operación tiene lugar en 1884, dejando a Sebastián Maltrana sin el resto de sus compañeros de lista; ello unido a la drástica reducción del censo que afectó, principalmente a sus asociados, se traducirá en 1886 en el retraimiento de un sector de comerciantes a la hora de apoyar a tres destacadas figuras del gremio, insertos en las candidaturas conservadora y liberal, mientras otro grupo refrendaba las de Coalición Republicana con altos porcentajes en Puerta del Sol y Arenal. El pulso entre élites institucionalizadas y fuerzas vivas locales está en su momento álgido $\mathrm{y}$, probablemente, fruto de la negociación fue el escaño obtenido por Salmerón en el Congreso. Las elecciones censitarias demuestran en Madrid el pacto permanente de los partidos oficiales con los únicos organismos capaces de plantear batalla electoral, bien desde los partidos del turno o a través de la oposición republicana. Ese año se creará la Cámara de Comercio e Industria de Madrid que en unión de otros organismos de representación económica, como el Círculo de la Unión Mercantil será polo de atracción de importantes intereses y lugar de permanentes enfrentamientos a las decisiones gubernamentales procedentes de presiones oligárquicas y monopolísticas. El acuerdo es posible gracias a la diversidad de los componentes del sector y a su especial idiosincrasia, entre el paternalismo gremial y el miedo a los excesos revolucionarios vividos durante el sexenio. 
Al llegar a la década de los noventa, la eclosión del voto popular refrendará a la coalición republicana entre la que estaban incluidos los intereses del grupo a través de Federico Ortiz y López, candidato republicano en 1891. Por otra parte, la lista liberal de ese año ofrecía en Madrid lo mejor del progresismo integrado en sus filas, como son las figuras de Canalejas y Moret ligadas a los centros culturales de la villa que, como el Ateneo, eran también «escuela de diputados de esa minoría liberal llamada a servir de pilar del sistema constitucional» ${ }^{55}$; incluía asimismo una figura liberal tan representativa de los intereses comerciales como Joaquín Angolotti y Merlo que presidía la Cámara de Comercio de la que había sido uno de sus promotores, además de ostentar el cargo de Director General de Hacienda en el Ministerio de Ultramar, ser diputado por la provincia de Puerto Rico y consejero del Banco Hispano Colonial hasta su muerte, dos años mas tarde. A partir de ese momento, el temor al desbordamiento de las bases electorales, difícilmente conjugable con su programa, llevará a integrar a Federico Ortiz con otra figura significativa como Ramón Saínz en la candidatura liberal de 1893, a raíz de la integración del republicanismo posibilista de Castelar en el fusionismo; el refrendo electoral a la lista liberal se vuelve unánime como demuestran los resultados obtenidos en la Puerta del Sol a favor de los candidatos. Pero otros intereses, los antillanos, priman en las esferas de poder y los representantes de las fuerzas vivas de la villa, no identificados con ellos, comenzarán a fraguar alternativas políticas al margen del turno institucionalizado, aunque el Partido Liberal intenta mantener las bases electorales de estas clases censitarias, ofreciendo a las mencionadas figuras hasta el final de siglo, con Pablo Ruiz de Velasco en la de 1898, sin olvidarnos de Mariano Sabas Muniesa, que estaba en las de 1901, mientras otros representantes de la vida económica madrileña integrados en el Círculo, optarán por la alternativa republicana de Constantino Rodríguez en las dos últimas elecciones del siglo, en momentos especialmente delicados, tanto para el Partido Liberal, como para el edificio de la Restauración ya que, en plena crisis colonial, las Ligas Agrarias de Gamazo le dejaban sin apoyo en el Parlamento y algunas clases medias madrileñas aspiraban a hacer oír su voz, en liz con las burguesías periféricas, al margen de los partidos del turno. Es la hora breve de la Unión Nacional madrileña cuyos nombres terminarán integrando candidaturas de las Uniones Monárquicas, opción conjunta de los partidos institucionales, bien por los liberales, como el citado Maltrana, o en nombre del Partido Conservador. 


\section{Elecciones en Madrid en el cambio de siglo}

El progresivo desencanto de amplias capas sociales cuyas aspiraciones no coincidían «con los lindes de los partidos que favorecían una reforma social moderada, porque compartían la creencia en la función ética del Estado...» ${ }^{56}$ desembocará en su inhibición ante el poder al no ser éste capaz de hacerlas partícipes de él. La proposición de Ley presentada por los diputados a Cortes de la provincia con el respaldo de los afiliados a la Cámara de Comercio, entre cuyos firmantes se hallaba el conocido Ramón Saínz, para exigir de la corporación municipal una retirada del impuesto de consumo en 1897 y $1898^{57}$ es ejemplo ilustrativo del Madrid parlamentario del periodo analizado.

Este hecho pone de relieve la importancia extrema del Ayuntamiento de la ciudad, foro de contiendas entre los organismos representativos de la "Villa», que pugnan por emerger, y una Capital que le utilizará como plataforma de lanzamiento a otras esferas de poder mientras afianza sus fortunas, en gran medida provenientes de la desamortización, con el afán de integrarse en la ansiada élite especulativa. Los componentes de este grupo irán en las listas de los partidos institucionales, en el Partido Conservador desde el principio y en el Liberal después, muchos de ellos ligados a los fabulosos negocios antillanos que ampliarán sus beneficios a través de los sillones del Parlamento, imponiendo las directrices del gobierno y serán los distintos intereses de las diferentes familias que configuran los partidos políticos los que tendrán en el Ayuntamiento uno de los escenarios de pugna. El presidido por el marqués de Cubas iniciará una investigación de la gestión de su antecesor, el conocido romerista Bosch y Fustegueras que le costará la jefatura de Gobierno a Cánovas; el inicial episodio de la batalla de Silvela por afianzarse en el partido frente a Romero Robledo, se consolidará a propósito de las elecciones parlamentarias de 1896 y 1898 en Madrid, a través de un extraño personaje, el marqués de Cabriñana que presenta su candidatura como independiente, quedándose a las puertas del triunfo en el primer intento hasta que consigue acta de diputado en la segunda ocasión. Es la carta silvelista en el momento de reorganizar el partido bajo su jefatura y preparar la alternancia de Sagasta bajo la bandera de «regeneración nacional». El relevo generacional que, en la década de los noventa, se producirá en el interior de las familias liberales dejará a Santiago Angulo fuera del encasillado de los diputados, procurándose el retiro en la alcaldía de Madrid. El grupo de jóvenes liberales que conforman las listas de esa década se mueven entre los negocios especulativos municipales y el afán de control de los díscolos organismos que, como el Círculo o la Cámara, daban muestran de desapego. 
Buena muestra de la mentalidad que conforma los objetivos de algunos de los candidatos será el hecho de que, viviendo en Madrid, han conseguido establecer su cacicato fuera de la capital obtenido en el trasiego desamortizador y pertenecen a uno de los sectores que condicionó la vida política madrileña de esa época, el de los propietarios del suelo y sus pingües beneficios especulativos, obtenidos con los planes de remodelación del espacio urbano, motivo de la denuncia de Cabriñana en 1898 y que provocarâ en Madrid la gran manifestación de «hombres honrados». Afincados en el Ayuntamiento, dictarán normas que expulsarán paulatinamente a amplios núcleos de población fuera del recinto de la villa. Fuertes monopolios industriales y comerciales, intereses especulativos de la Banca y el desarrollo urbanístico del suelo alejan lentamente a las bases electorales de unos partidos institucionales en los que no creen tener cabida.

\section{Notas}

1 AVS 9-287-1, AVS 9-288-1 y AVS 9-288-5 para $\mathrm{n}^{\circ}$ de secciones. Palacio: 24 secciones (1 a 24); Universidad: 29 secciones (25 a 53): Centro: 13 secciones (54 a 66); Hospicio: 27 secciones (67 a 93); Buenavista: 30 secciones (94 a 123); Congreso: 15 secciones (124 a 138); Hospital: 25 secciones (139 a 163); Inclusa: 24 secciones (164 a 187); Latina: 24 secciones (188 a 211); Audiencia: 16 secciones (212 a 227). Emilio Valverde: Plano y guía del viajero de Madrid, Madrid 1885, p. 107, 108.

2 A.V.S. 9-287-1, 9-288-2: $\mathrm{n}^{\circ}$ de electores 103.894. 103.000 según La Época 2 febrero de 1890. El censo de población de 1887 arrojaba un total de 470.283 habitantes. En 1900, había ascendido a 539.835 personas que vivían en Madrid.

Ante una población incrementada en 116.760 habitantes respecto al censo de $\mathbf{1 8 7 7}$, el número de electores ha aumentado en sólo 12.214 en relación a las anteriores elecciones de 1876 celebradas también por sufragio universal, lo que hace suponer que más de una reclamación quedó sin atender a la hora de confeccionar las listas. La manipulación del censo es una constante habitual observada en todos los comicios.

3 En el distrito de Hospital tiene fijada su residencia Fernando Corradí, propietario y candidato moderado en 1876 (calle Lope de Vega, 45), Guillermo Escribá de Romaní (C/. Atocha, 36) y Romualdo Céspedes (C/. Magdalena, 4).

4 Viven en ellas José Cánovas del Castillo (C/. Horno de la Mata, 16), Manuel Tamayo y Baus (C/. Valverde, 26), Manuel Gasset y Mercader (C/. Horno de la Mata, 7, en las proximidades de Arenal, Antonio Cánovas del Castillo (C/. Fuencarral, 4 hasta su traslado a la finca de la Huerta, a raíz de su boda con Joaquina Osma), Juan Utrilla, candidato independiente de 1876 y Teodoro Bonaplata, candidato conservador en 1896, el primero en Plaza de Santa Barbara, 2 y en Habana, 5, el segundo. La sección de Escorial alberga algún rico comerciante, como el industrial chocolatero Matías López y López (C/. Palma Alta, 8). 


\section{Elecciones en Madrid en el cambio de siglo}

5 Antonio Fernández García, «La población madrileña entre 1876 y 1931. El cambio de modelo demográfico", en la Sociedad Madrileña durante la Restauración 1876-1931. Volumen I p. 33.

Antonio Camarero, "Madrid finisecular nuevo modelo demográfico" en "Madrid en la Sociedad del S. XIX", Vol. 2. Comunidad de Madrid, p. 299.

Amando de Miguel, "La población de Madrid en los primeros años de siglo", Revista española de investigaciones sociológicas, p. 69.

Carmen del Moral, "La ciudad de Madrid a finales del siglo XIX», Madrid, Turner, 1974 , p. 50. La autora se refiere a las pirámides de población de 1887 y 1900.

6 Los centros de propaganda republicana se activan para movilizar al electorado; cada grupo tiene distintos locales; los federales tienen uno en la $\mathrm{C} /$ Costanilla de los Angeles $\mathrm{n}^{\circ} 1$. Los centralistas de Figueras en C/ Carmen 14 y C/ Alcalá12, los progresistas de Ruiz Zorrilla en Esparteros. Así en períodos electorales anteriores, este núcleo geográfico fue denominado "el bolsín republicano". El Círculo de la constituida Unión Republicana organizó sus locales para reuniones electorales en la C/ Arenal, 1. En los otros distritos estaban ubicados en la C/ Encomienda (Inclusa), C/ Príncipe de Vergara en el barrio de la Plaza de Toros (Buenavista) y Bellas .Vistas, Cuatro Caminos en zona casi suburbana. Las Juntas de barrio mas activas de los republicanos federales y con una presencia real en los mismos, eran las de Pozas, Daoíz y Segovia. Había el mismo tipo de organizaciones progresistas en: Progreso, Cava Baja, Juanelo, Estudios, Concepción, Pta. Cerrada, Constitución y Carretas.

7 Para la campaña electoral: $L a$ Época, días $12,18,20,21,25$ y 31 de enero de 1891. El País, días 7, 9, 17, 18, 28 y 29 de enero de 1891. La Iberia, días 24, 26, 27 de enero. El Globo, 15 y 21 de enero. El Imparcial, 27 de enero de 1891.

8 Presentados de esta suerte por La Época, 18 de enero de 1891: Pablo Iglesias, cajista, verbo de socialismo, pontífice de la Iglesia Ortodoxa; enemigo declarado, intransigente de todo burgués. José Bear marmolista, presidente del grupo de marmolistas. Julián Padilla y Navarro, carpintero joven que ha fundado la sociedad "La Unión", para favorecer la resistencia de los afiliados en los momentos de lucha. Manuel González y González, 50 años y presidente de la unión de cerrajeros. gran ascendiente entre la clase trabajadora. José Agulló, joven de gran actividad y socialista empedernido. Saturnino González Villa, albañil joven y de gran entusiasmo. preside la sociedad del trabajo y es orador del grupo de albañiles.

9 B.O.P.M. Suplemento al $\mathrm{n}^{\circ} 28$, correspondiente al lunes 2 de febrero de 1891. A.V.S. $10-477-5$.

10 A.V.S. 10-477-1.

11 Angel Bahamonde Magro y Joaquín Toro Mérida, "Burguesía, especulación y cuestión social en el Madrid del siglo XIX", Madrid, Siglo XXI, 1978, pp. 148, 149.

12 La Época 23 de febrero de 1.893. Manifiesto del Comité Electoral Católico. Sus centros electorales estaban ubicados en S.Miguel,19- dup; Ayala, 46-bajo; Luna,29bajo; Nuncio, b.19.

13 Para la campaña electoral: La Época 6, 8, 11, 12, 16 y 17 de febrero de 1893, La República 2 de febrero. El Imparcial 8 y 10 de febrero. El País 5, 6, 9, 19, 25 de febrero y 4 de Marzo de 1893.

14 El País 6 de marzo de 1893.

15 Boletín Oficial de la Provincia de Madrid. Suplemento $\mathrm{n}^{\circ} 55$ correspondiente al lunes 6 de marzo de 1893. Las actas del Archivo de la Villa difieren poco de las del Boletín con 159.312 votos, igual que las del Archivo de Cortes que arrojan una 


\section{Amparo García López}

cifra de 159.311. Sorprendentemente aparecen mas infladas en el periódico conservador La Época 5 de marzo con un total de 159.640 votos republicanos. Ello induce a aceptar la tesis de los que ven en el triunfo republicano de Madrid una complicidad conservadora, empezando por su inhibición electoral, en aras del descalabro del Partido Liberal.

16 El País 7 de marzo de 1893.

17 El País y La Época 7 de marzo de 1893.

18 Bahamonde Magro, A. y Toro Mérida, J.: «Burguesía...», op. cit., pp. 143 a 145.

19 A.V.S. 6-148-7.

20 A.V.S. 7-345-11.

21 Una denuncia del Marqués de Cabriñana, el 13 de octubre de 1895, hizo revivir la fétida cuestión del Ayuntamiento de Madrid en 1892. En esta ocasión, el escándalo se produce a raíz de la subasta de unos solares en la calle Sevilla y de varias irregularidades en el ensanche, Casa de Vacas del Retiro y Consumos. El encausado es Leopoldo Galvéz Holquín, concejal romerista y por tanto relacionado con el Ministro de Gobernación, Romero y Robledo reconciliado con Cánovas, a raíz de la ruptura de Silvela con el jefe del partido conservador.

22 La Época, 27, 29 y 30 de marzo de 1896.

$23 \mathrm{La}$ única voz republicana que defendió la guerra independentista fue la de Pi y Margall.

24 Boletín Oficial de la Provincia de Madrid. Suplemento al número 89, correspondiente al lunes 13 de abril de 1896.

25 Nuria Sales: «Sobre esclavos, reclutas y mercaderes de quintos», Barcelona, Ariel, 1974.

26 La Iberia, 15 de abril de 1896.

27 El Pais, 15 de abril de 1896.

28 E. Prugent, "Los hombres de la Restauración", Madrid, 1880, p.263. También Angel Bahamonde Magro y otros, «La Cámara de Comercio e Industria de Madrid (1887-1987)", Madrid, Cámara de Comercio e Industria de Madrid 1988, p. 101.

29 Manuel Tuñón de Lara, "Estudios sobre el siglo XIX español», Madrid, Siglo XXI, 1974, $3^{\text {a }}$ edición, pp. $181,184,185$, refiriéndose a "La otra burguesía", de carácter medio, no oligárquica y considerada heterodoxa por el autor.

30 Carlos Serrano, "Final del Imperio. España 1895-1898». Madrid, Siglo XXI, 1984 , p. 42.

31 El 23 de junio de 1898, Romero Robledo exigía al Gobierno en el Congreso la defensa de los sagrados intereses de la Patria, llevando a cabo una guerra a la desesperada. Diario de Sesiones del Congreso, pp. 1652 a 1654, en García Escudero, José $\mathrm{M}^{\mathrm{a}}$ : «De Cánovas a la República». Editorial Rialp 1951, p. 118. «Colección de documentos referentes a la escuadra de operaciones de las Antillas ordenados por el Almirante Cervera". Madrid, Editorial Naval, 1986, p. 134. Dicha colección había podido ser publicada por D. Pascual Cervera y Topete, el 30 de agosto de 1899, al perder su carácter secreto. Muestra la subordinación y aceptación de un deber impuesto con disciplina y lealtad. Véase, asimismo, Alberto Risco, P.: «Apuntes biográficos del Excmo. Sr. D. Pascual Cervera Topete», Toledo, 1920. Rodríguez Martínez, Félix: "Los desastres y la regeneración de España». La Coruña 1899.

32 Buen ejemplo de ello es que la escuadra de Cervera llevaba cinco cruceros auxiliares facilitados por la Trasatlántica. La Compañía era propiedad del marqués de Comillas como concesión de Romero y Robledo desde el gobierno. El Marqués estaba emparentado con los Güell y Ferrer y compartían con los Girona la hegemonía 
del Banco Hispano Colonial, el de Castilla y de la Compañía de Tabacos de Filipinas, en: Manuel Tuñón de Lara, "Estudios...», op. cit., p.173. El libro facilita una importante investigación del complejo entramado de intereses oligárquicos, entre ellos el del lobby cubano, resaltando, por otra parte, el control norteamericano del mercado cubano en la guerra larga de 1868-1878.

33 El periódico publica los resultados electorales, acompañados del mencionado comentario. El Imparcial, lunes 28 de marzo de 1898.

34 El País 28 de marzo de 1898.

35 «Quedan verdaderas incógnitas, respecto a la familia Canalejas que integrada en los intereses de los "pequeños ferrocarriles" le habían situado frente a los de tendencia monopolística y sus contradicciones con la oligarquía incluso hasta su muerte, de Jefe de Gobierno. Nadie ignora que Canalejas es un hombre clave en la encrucijada de caminos, y pudo serlo aún más; tampoco que su formación fue Krausista, por su tío Francisco de Paula Canalejas...». Tuñón de Lara, Manuel, Estudios... op. cit., pp. 186, 187.

36 El número de secciones se amplía a 238. La Época 22 de marzo de 1899.

37 La Época 15 de abril de 1899.

38 La Época, 10 y 22 de marzo de 1899. El Imparcial, 21 de marzo de 1899.

39 La Época, 22 de marzo de 1899.

40 La Época, 22 de marzo de 1899.

41 Boletín Oficial de la Provincia de Madrid, suplemento al $n^{\circ} 91$, correspondiente al lunes 17 de abril de 1899.

42 La Época, 12, 13 de marzo y 16 de abril de 1899: "mitin socialista en Bilbao"; "el discurso socialista»; "partidos ridículos".

43 La Época, 15 de abril «Las Cortes de la paz»; 11 de marzo, 7 y 13 de abril de 1899: "La amenaza carlista»; "Fracaso de los carlistas"; 22 de marzo "Lo que dice el Sr. Paraíso»; 14 de abril "Las ideas del Sr. Costa»; 16 y 21 de marzo: "Huelga de cocheros en Madrid»; 12 de abril "Discursos de los grandes de España»; 14, 15 y 28 de marzo y 11 de abril: "La guerra en Filipinas, el tratado de paz, la conferencia de Desarme y el caso Dreyfus".

44 Ley de accidentes de trabajo, 30 de enero 1900, trabajo de mujeres y niños, 13 de marzo.

45 A. Bahamonde Magro y otros, «La Cámara...», op. cit., pp. 120, 121.

46 El Liberal 15 de mayo de 1901.

47 Corriente regeneracionista que funde las aspiraciones nacionales de la clase media agrícola o comerciante de Castilla y Aragón, fundada en una asamblea de las Cámaras de Comercio, reunidas en Valladolid el 14 de enero de 1900. Sus dirigentes mantienen criterios opuestos sobre su función política: constituirse en un grupo de presión dentro de los partidos tradicionales o la de ser una fuerza política de centro, entre las dos turnantes. La Liga de Productores se unirá a la Unión Nacional, formándose un directorio integrado por Basilio Paraíso, Joaquín Costa y Santiago Alba.

Según Fernández Almagro, no supo erigirse en fuerza neutral auxiliadora, ni emprender el largo camino de la propaganda cívica y prefirió los atajos de la agitación mafiosa: el arma de resistencia al pago de tributos bastaría para liquidar al Partido Conservador y tratar posteriormente el reparto del poder con los liberales.

48 El Imparcial 15 de abril de 1884: se pregunta en un mitin celebrado con motivo de las elecciones de ese año si los hombres como él no tienen derecho a intervenir en la administración del país.

49 Angel Bahamonde Magro y otros, «La Cámara de Comercio... op. cit., p. 103. 


\section{Amparo García López}

50 La Época 21, 22 de abril, 12 y 16 de Mayo de 1901. El Liberal 12, 13, 17 y 19 de mayo de 1901.

51 Boletín Oficial de la Provincia de Madrid. Suplemento al $\mathrm{n}^{\circ} 120$ correspondiente al lunes 20 de mayo de 1901.

52 El Liberal 20 de mayo de 1901: Elecciones Generales en Madrid.

53 Guillermo Cortázar, "La nobleza en Madrid en la época de la Restauración", en Madrid en la sociedad del siglo XIX, pp. 558-566. Angel Bahamonde Magro, "Crisis de la nobleza de cuna y consolidación burguesa (1840-1880)", en Madrid ..., p. 344.

54 El Imparcial, 14, 16, 18 y 19 de agosto de 1881.

55 Manuel Espadas Burgos, "Madrid. Centro de poder político", en Madrid en la Sociedad del S. XIX, Tomo I, p. 191.

56 Raymond Carr, «España 1808-1939», Barcelona, Ariel, 1969, p. 440.

57 El Liberal, 7 de diciembre de 1900. 